\title{
In Silico Ligand-Based Methods Targeting Porcupine Receptor Inhibitors with Potential Anticancer Effect ${ }^{\dagger}$
}

\author{
Ana Borota * and Luminita Crisan * \\ Institute of Chemistry, Romanian Academy, Mihai Viteazul Avenue, 24, 300223 Timisoara, Romania \\ * Correspondence: ana_borota@acad-icht.tm.edu.ro (A.B.); lumi_crisan@acad-icht.tm.edu.ro (L.C.) \\ + Presented at the 22nd International Electronic Conference on Synthetic Organic Chemistry, 15 November-15 \\ December 2018; Available Online: https://sciforum.net/conference/ecsoc-22.
}

Published: 14 November 2018

\begin{abstract}
Porcupine is a protein belonging to the O-acyltransferase family, involved in the catalyzing of palmitoylation of wingless-related integration (WNT) proteins. WNT signaling has significant roles in many physiological functions, e.g., hematopoiesis, homeostasis, neurogenesis, and apoptosis. Anomalous WNT signaling has been observed to be related to tumor generation, and metabolic and neurodegenerative disorders. Therefore, compounds that inhibit this pathway are of great interest for the development of therapeutic approaches. For a better understanding of the common traits of such compounds, we have undertaken an in silico study in order to develop a valid ligand-based pharmacophore model based on a series of porcupine inhibitors. The best pharmacophore hypothesis found after the 3D QSAR validation process is represented by the following features: one hydrogen bond donor $(\mathrm{D})$, three rings $(\mathrm{R})$ and one hydrophobic centroid $(\mathrm{H})$. The 3D-QSAR model obtained using the DRRRH hypothesis shows statistically significant parameters: correlation coefficients for the training set: $\mathrm{R}^{2}$ of 0.90 , and a predictive correlation coefficient for the test set, $\mathrm{Q}^{2}$ of 0.86 . The assessment of the pharmacophore model was also done and provided very reliable metrics values (Receiver Operating Characteristic-ROC of 1; Robust Initial Enhancement-RIE of 17.97). Thereby, we obtained valuable results which can be further used in the virtual screening process for the discovery of new active compounds with potential anticancer activity.
\end{abstract}

Keywords: Porcupine (PORCN) inhibitors; pharmacophore; 3D-QSAR

\section{Introduction}

Porcupine (PORCN) is a protein belonging to the O-acyltransferase family, resident in the endoplasmatic reticulum, involved in the catalyzing of palmitoylation of wingless-related integration (WNT) proteins [1]. This palmitoylation is essential for WNT secretion and signaling [2,3]. The plethora of roles in which WNT signaling is involved include among others: tissue and intestinal homeostasis [4,5], hematopoiesis [6], cell migration [7], and apoptosis [8,9]. Dysregulation of WNT signaling has been observed to be correlated with tumor generation [10,11], metabolic disease [12], fibrosis [13], and neurodegenerative disorders [9,14]. It has been observed that a subset of cancers (colon, ovarian, esophageal, lung, heart, and neck cancers) are related to enhanced cellular sensitivity to WNT $[2,15,16]$.

One way to handle the secretion of WNT is by inhibiting the activity of the PORCN enzyme which has the role in lipid modification of WNT and in WNT biogenesis, its genetic deletion leading to embryonic death $[17,18]$.

The development of PORCN inhibitors being at the beginning of the road, it is space for new and elaborate research in this field of study. 
Thus, in order to computationally explore the specific features of PORCN inhibitors with potential anticancer effect, a series of recently synthesized and tested PORCN antagonists [1] were taken in our study. Ligand-based pharmacophore modeling is mostly used, like in this case, when the 3D structure of the target is not available. The identification of the pharmacophoric features of the ligands required for the molecular recognition by their target (PORCN receptor) was explored using Phase software [19] from the Schrödinger suite [https://www.schrodinger.com].

\section{Materials and Methods}

\subsection{Ligand Preparation}

A dataset of 17 compounds [1] which act as inhibitors on PORCN receptors was the subject of computational analysis for pharmacophore generation. The 2D structures of the compounds were drawn with Marvin Sketch (version 17.18), from Chemaxon [http://www.chemaxon.com]. The ligand preparation was realized using Ligprep software [20] of Schrödinger. The optimization of the structures was achieved with OPLS_2005 force field, the ionization with Epik [21] using a pH of 7.2 \pm 0.2 criterion, and the tautomers and stereoisomers were also obtained.

\subsection{Pharmacophore Generation and Validation}

Phase [19] with the option: "Develop Common Pharmacophore Hypotheses" was used for the generation and validation of the pharmacophore hypotheses by the involvement of the Atom-based QSAR module. ConfGen [22] was engaged in the generation of multiple conformers for each compound using default settings. The compounds were considered active if the $\mathrm{pIC}_{50}$ value is higher than 8 and inactive if the pIC50 value is lower than 7. An Atom-based 3D-QSAR [23] analysis was carried out by using 1 partial least-squares (PLS) factor and a test set of approx. $28 \%$ of compounds was employed. Additionally, a "Validate hypothesis workflow" option was used for scoring of all the resulted hypotheses [https://www.schrodinger.com]. The compounds of the dataset used to develop the pharmacophore models are shown in Table 1 along with their experimental and predicted activity.

Table 1. The Smiles code of porcupine (PORCN) inhibitors from the dataset [1] along with their activity (experimental and predicted) and the QSAR set distribution.

\begin{tabular}{|c|c|c|c|}
\hline ID & Smiles Code & pIC50exp & pIC50pred \\
\hline $1 *$ & Cc1cc(ccn1)c2ccc(cc2)CC $(=\mathrm{O}) \mathrm{Nc} 3 \operatorname{ccc}(\operatorname{cc} 3) \operatorname{c4} 4 \mathrm{cccc} 4$ & 8.54 & 8.47 \\
\hline 2 & $\mathrm{c} 1 \mathrm{ccc}-2 \mathrm{c}(\mathrm{c} 1) \mathrm{Cc} 3 \mathrm{c} 2 \mathrm{ccc}(\mathrm{c} 3) \mathrm{CC}(=\mathrm{O}) \mathrm{Nc} 4 \mathrm{ccc}(\mathrm{cc} 4) \mathrm{c} 5 \mathrm{cccnc} 5$ & 6.64 & 6.56 \\
\hline 3 & $\mathrm{c} 1 \mathrm{ccc} 2 \mathrm{c}(\mathrm{c} 1) \mathrm{c} 3 \mathrm{ccc}(\mathrm{cc} 3 \mathrm{o} 2) \mathrm{CC}(=\mathrm{O}) \mathrm{Nc} 4 \mathrm{ccc}(\mathrm{cc} 4) \mathrm{c} 5 \mathrm{cccnc} 5$ & 6.26 & 6.51 \\
\hline 4 & $\mathrm{c} 1 \mathrm{ccc}-2 \mathrm{c}(\mathrm{c} 1) \mathrm{Cc} 3 \mathrm{c} 2 \mathrm{ccc}(\mathrm{c} 3) \mathrm{CC}(=\mathrm{O}) \mathrm{Nc} 4 \mathrm{ccc}(\mathrm{cn} 4) \mathrm{c} 5 \mathrm{cnccn} 5$ & 6.34 & 6.62 \\
\hline 5 & $\operatorname{c1ccc} 2 \mathrm{c}(\mathrm{c} 1) \operatorname{c} 3 \operatorname{ccc}(\mathrm{cc} 3 \mathrm{o} 2) \mathrm{CC}(=\mathrm{O}) \mathrm{Nc} 4 \mathrm{ccc}(\mathrm{cn} 4) \mathrm{c} 5 \mathrm{cnc} \operatorname{cn} 5$ & 6.87 & 6.53 \\
\hline $6^{*}$ & Cc1cc(cnc1c2ccnc(c2)C)CC $(=\mathrm{O}) \mathrm{Nc} 3 \mathrm{ccc}-4 \mathrm{c}(\mathrm{c} 3) \mathrm{Cc} 5 \mathrm{c} 4 \mathrm{cccc} 5$ & 8.60 & 8.89 \\
\hline $7 *$ & $\mathrm{Cc} 1 \mathrm{cc}(\mathrm{cnc} 1 \mathrm{c} 2 \mathrm{ccnc}(\mathrm{c} 2) \mathrm{C}) \mathrm{CC}(=\mathrm{O}) \mathrm{Nc} 3 \mathrm{ccc}-4 \mathrm{c}(\mathrm{c} 3) \mathrm{C}(\mathrm{c} 5 \mathrm{c} 4 \mathrm{cccc} 5)(\mathrm{F}) \mathrm{F}$ & 8.57 & 8.92 \\
\hline 8 & $\mathrm{Cc} 1 \mathrm{cc}(\operatorname{cnc} 1 \mathrm{c} 2 \mathrm{ccnc}(\mathrm{c} 2) \mathrm{C}) \mathrm{CC}(=\mathrm{O}) \mathrm{Nc} 3 \operatorname{ccc} 4 \mathrm{c}(\mathrm{c} 3)-\mathrm{c} 5 \operatorname{ccccc} 5 \mathrm{C} 4=\mathrm{O}$ & 8.55 & 8.86 \\
\hline 9 & Cc1cc $(\operatorname{cnc} 1 \mathrm{c} 2 \operatorname{ccn} c(\mathrm{c} 2) \mathrm{C}) \mathrm{CC}(=\mathrm{O}) \mathrm{Nc} 3 \operatorname{ccc} 4 \mathrm{c} 5 \operatorname{ccccc} 5[\mathrm{nH}] \mathrm{c} 4 \mathrm{c} 3$ & 8.59 & 8.78 \\
\hline 10 & $\mathrm{Cc} 1 \mathrm{cc}(\mathrm{ccn} 1) \mathrm{c} 2 \mathrm{ccc}(\mathrm{cc} 2) \mathrm{CC}(=\mathrm{O}) \mathrm{Nc} 3 \mathrm{ccc}-4 \mathrm{c}(\mathrm{c} 3) \mathrm{Cc} 5 \mathrm{c} 4 \mathrm{cccc} 5$ & 8.85 & 8.85 \\
\hline 11 * & $\operatorname{c1ccc} 2 c(c 1)-\operatorname{coccc}(\operatorname{cc} 3 \mathrm{C} 2=\mathrm{O}) \mathrm{CC}(=\mathrm{O}) \mathrm{Nc} 4 \operatorname{ccc}(\operatorname{cc} 4) \operatorname{c5cccnc} 5$ & 6.00 & 6.62 \\
\hline 12 & $\mathrm{Cc} 1 \mathrm{cc}(\mathrm{ccn} 1) \mathrm{c} 2 \mathrm{ccc}(\mathrm{cc} 2) \mathrm{CC}(=\mathrm{O}) \mathrm{Nc} 3 \mathrm{ccc}-4 \mathrm{c}(\mathrm{c} 3) \mathrm{C}(\mathrm{c} 5 \mathrm{c} 4 \mathrm{cccc} 5)(\mathrm{F}) \mathrm{F}$ & 8.46 & 8.46 \\
\hline 13 & $\mathrm{Cc} 1 \mathrm{cc}(\mathrm{ccn} 1) \mathrm{c} 2 \mathrm{ccc}(\mathrm{cc} 2) \mathrm{CC}(=\mathrm{O}) \mathrm{Nc} 3 \mathrm{ccc}-4 \mathrm{c}(\mathrm{c} 3) \mathrm{C}(=\mathrm{O}) \mathrm{c} 5 \mathrm{c} 4 \mathrm{cccc} 5$ & 9.35 & 8.88 \\
\hline 14 & $\mathrm{Cc} 1 \mathrm{cc}(\operatorname{ccn} 1) \operatorname{coccc}(\operatorname{cc} 2) \mathrm{CC}(=\mathrm{O}) \mathrm{Nc} 3 \operatorname{ccc} 4 \operatorname{coc} \operatorname{cccc} 5[\mathrm{nH}] \mathrm{c} 4 \mathrm{c} 3$ & 8.64 & 8.44 \\
\hline $15^{*}$ & $\operatorname{c1ccc} 2 c(\mathrm{c} 1)-\mathrm{c} 3 \operatorname{ccc}(\operatorname{cc} 3 \mathrm{C} 2=\mathrm{O}) \mathrm{CC}(=\mathrm{O}) \mathrm{Nc} 4 \mathrm{ccc}(\mathrm{cn} 4) \mathrm{c} 5 \mathrm{cnc} \operatorname{cn} 5$ & 6.00 & 6.72 \\
\hline 16 & $\mathrm{Cc} 1 \mathrm{cc}(\operatorname{ccn} 1) \operatorname{c2} \operatorname{ccc}(\mathrm{cc} 2) \mathrm{CC}(=\mathrm{O}) \mathrm{Nc} 3 \operatorname{ccc} 4 \mathrm{c} 5 \operatorname{ccccc} 5 \mathrm{oc} 4 \mathrm{c} 3$ & 8.05 & 8.05 \\
\hline 17 & $\mathrm{Cc} 1 \mathrm{cc}(\mathrm{cnc} 1 \mathrm{c} 2 \mathrm{ccnc}(\mathrm{c} 2) \mathrm{C}) \mathrm{CC}(=\mathrm{O}) \mathrm{Nc} 3 \mathrm{ccc}(\mathrm{cn} 3) \mathrm{c} 4 \mathrm{cnccn} 4$ & 9.05 & 8.36 \\
\hline
\end{tabular}

* denotes the compounds from the test set.

\section{Results and Discussions}

The best pharmacophore obtained is represented by DRRRH hypothesis depicted in Figure 1 and its statistical parameters are presented in Table 2. Pharmacophore sites for DRRRH hypothesis consist of a set of chemical features: one hydrogen donor (D), three aromatic rings (R) and one 
hydrophobic $(\mathrm{H}) . "$ The correlation plot of experimental versus predicted activity is shown in Figure 2. The important features for the ligand-receptor interactions are displayed in Figure 3.

Table 2. The statistical parameters for the best pharmacophore hypothesis (DRRRH).

\begin{tabular}{cccccccccc}
\hline Hypothesis & $\mathbf{S D}$ & $\mathbf{R}^{2}$ & $\mathbf{R}^{2} \mathbf{c v}$ & $\mathbf{R}^{2}$ scramble & Stability & $\mathbf{F}$ & RMSE & $\mathbf{Q}^{2}$ & Pearson- $\mathbf{R}$ \\
\hline DRRRH & 0.37 & 0.90 & 0.76 & 0.44 & 0.94 & 88.60 & 0.47 & 0.86 & 0.99 \\
\hline
\end{tabular}

SD-standard deviation of the regression, $\mathbf{R}^{2}-$ value of $\mathbf{R}^{2}$ for the regression, $\mathbf{R}^{2} \mathbf{C V}-$ Cross-validated $R^{2}$ value, computed from predictions obtained by a leave-N-out approach, $\mathbf{R}^{2}$ scramble-average value of $\mathrm{R} 2$ from a series of models built using scrambled activities (measures the degree to which the molecular fields can fit meaningless data, and should be low), Stability of the model predictions to changes in the training set composition (this statistic has a maximum value of 1 -meaning stable). Fvariance ratio, RMSE - root mean squared error of the test set, $\mathbf{Q}^{2}$-value of $\mathrm{Q}^{2}$ for the predicted activities of the test set, Pearson-R - value of Pearson-R for test predicted activities of the test set [24].

The atom type fractions resulted for our pharmacophore hypothesis (DRRRH) are 0.01 for Hbond donor, 0.69 for hydrophobic/non-polar and 0.30 for electron-withdrawing. The best-fitted compound (no. 10) with fitness score value of 3 is also the second-best compound as activity in the series (Table 1). The distances between all the pharmacophore features are presented in Table 3.

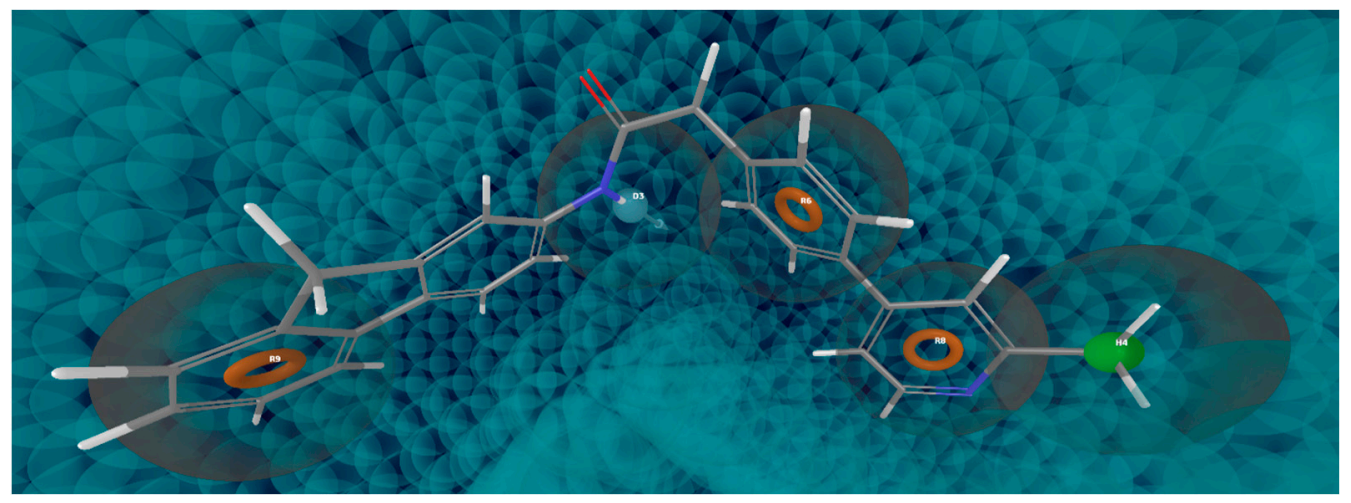

Figure 1. Compound 10, the best fitted on DRRRH hypothesis.

Table 3. Inter-feature distances for DRRRH hypothesis.

\begin{tabular}{ccc}
\hline Site $\mathbf{1}$ & Site 2 & Distance $(\AA)$ \\
\hline R9 & D3 & 7.54 \\
R9 & R6 & 10.30 \\
R9 & R8 & 12.83 \\
R9 & H4 & 15.16 \\
D3 & R6 & 3.62 \\
D3 & R8 & 7.39 \\
D3 & H4 & 9.80 \\
R6 & R8 & 4.34 \\
R6 & H4 & 6.36 \\
R8 & H4 & 2.87 \\
\hline
\end{tabular}




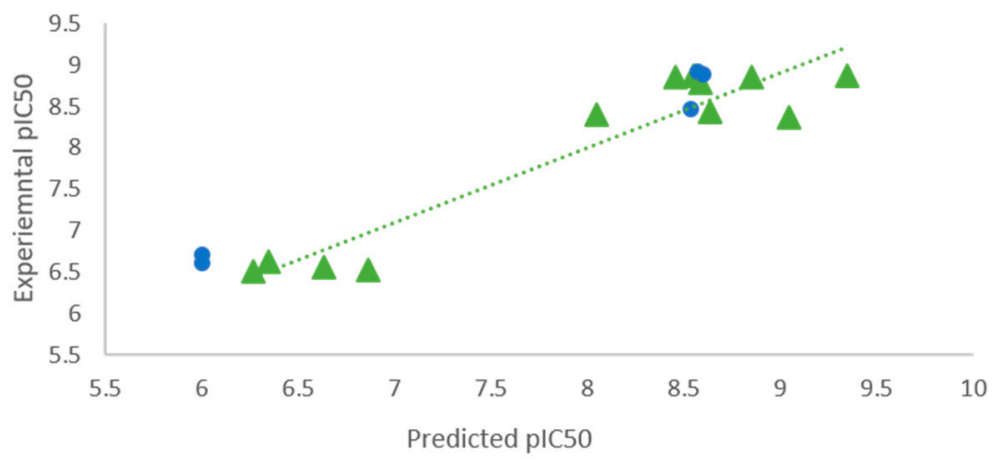

Figure 2. Correlation plot of experimental versus PHASE software [19] predicted activity of training set (green triangles circles) and test set (blue circles).

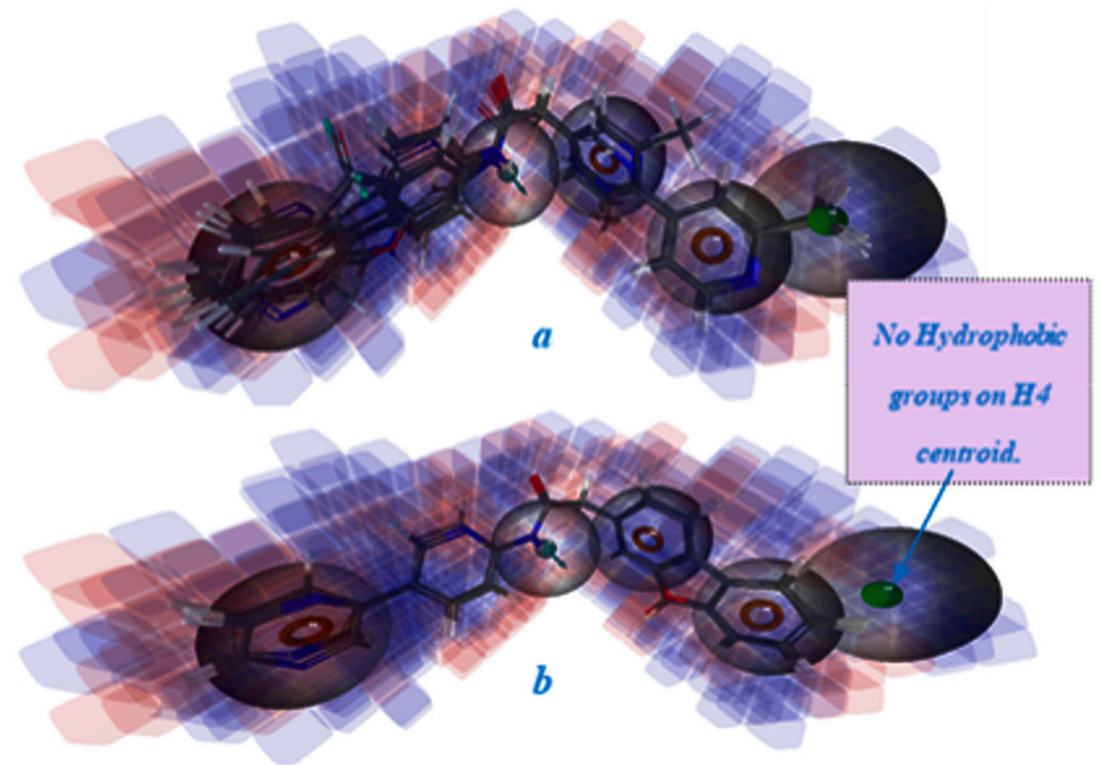

Figure 3. The data set compounds in the context of 3D-QSAR model with: hydrogen bond donor, hydrophobic and electron-withdrawing properties represented. (a) The active compounds aligned over DRRRH hypothesis; (b) The inactive compounds aligned over DRRRH hypothesis. Blue cubes indicate positive coefficient (increase in activity), red cubes indicate negative coefficient (decrease in activity).

Enrichment performance for all hypotheses generated were performed using the "Validate hypothesis workflow" from Phase [19]. Based on these results we are able to identify the most significant hypothesis which satisfy the goals of a virtual screening analysis. For the DRRRH pharmacophore hypothesis, the significant metric values were obtained (Table 4).

Table 4. Enrichment performance for the DRRRH pharmacophore hypothesis *.

\begin{tabular}{ccc}
\hline \multicolumn{3}{c}{ BEDROC } \\
\hline Alpha $=160.9$ & Alpha $=20.0$ & Alpha $=8.0$ \\
\hline 1.000 & 1.000 & 1.000 \\
\hline \multicolumn{3}{c}{ alpha* Ra } \\
\hline 1.751 & 0.218 & 0.087 \\
\hline \multicolumn{2}{c}{ Receiver Operator Characteristic (ROC) } \\
\hline \multicolumn{2}{c}{1.000} \\
\hline \multicolumn{2}{c}{ Area under accumulation curve (AUAC) } \\
\hline \multicolumn{2}{c}{0.990} \\
\hline
\end{tabular}


Table 4. Cont.

\begin{tabular}{|c|c|c|}
\hline \multicolumn{3}{|c|}{ Robust Initial Enhancement (RIE) } \\
\hline \multicolumn{3}{|c|}{17.970} \\
\hline \multicolumn{3}{|c|}{ Count and percentage of actives in top N\% of decoy results } \\
\hline \multicolumn{3}{|c|}{$\%$ Decoys } \\
\hline $1 \%$ & $2 \%$ & $5 \%$ \\
\hline \multicolumn{3}{|c|}{$\%$ Actives } \\
\hline 100 & 100 & 100 \\
\hline \multicolumn{3}{|c|}{ Count and percentage of actives in top $\mathrm{N} \%$ of results } \\
\hline \multicolumn{3}{|c|}{$\%$ Results } \\
\hline $1 \%$ & $2 \%$ & $5 \%$ \\
\hline \multicolumn{3}{|c|}{$\%$ Actives } \\
\hline 90.9 & 100 & 100 \\
\hline \multicolumn{3}{|c|}{ Enrichment Factors with respect to N\% sample size. } \\
\hline \multicolumn{3}{|c|}{$\%$ Sample } \\
\hline $1 \%$ & $2 \%$ & $5 \%$ \\
\hline \multicolumn{3}{|c|}{ Enrichment factor (EF) } \\
\hline $92 \%$ & $51 \%$ & $20 \%$ \\
\hline \multicolumn{3}{|c|}{ Enrichment factor for recovering $\mathrm{x} \%$ of the known actives $\left(\mathrm{EF}^{*}\right)$} \\
\hline $1 \mathrm{e}+02$ & 50 & 20 \\
\hline \multicolumn{3}{|c|}{ Modified enrichment factor $\left(\mathrm{EF}^{\prime}\right)$} \\
\hline $1.8 \mathrm{e}+02$ & 95 & 39 \\
\hline \multicolumn{3}{|c|}{ Efficiency in distinguishing actives from decoys (Eff) } \\
\hline 0.980 & 0.961 & 0.905 \\
\hline
\end{tabular}

“*”BEDROC - Boltzmann-enhanced Discrimination Receiver Operator Characteristic area under the curve. The value is bounded between 1 and 0 , with 1 being ideal screen performance. The default alpha $=20$ weights the first $\sim 8 \%$ of screen results. When alpha* $\mathrm{Ra}<<1$, where $\mathrm{Ra}$ is the radio of total actives to total ligands, and alpha is the exponential prefactor, the BEDROC metric takes on a probabilistic meaning. Calculated as described by Truchon, J. F.; Bayly, C. I. J. Chem. Inf. Model. 2007, 47, 488-508, Equation (36); ROC-Receiver Operator Characteristic area under the curve. The value is bounded between 1 and 0 , with 1 being ideal screen performance and 0.5 reflecting random behaviour. Calculated as described by Truchon, J. F.; Bayly, C. I. J. Chem. Inf. Model. 2007, 47, 488-508, Equation (A.8); AUAC-Area Under the Accumulation Curve. The value is bounded between 1 and 0 , with 1 being ideal screen performance. Calculated as described by Truchon, J. F.; Bayly, C. I. J. Chem. Inf. Model. 2007, 47, 488-508, Equation (8); RIE-Robust Initial Enhancement. Active ranks are weighted with a continuously decreasing exponential term. Large positive RIE values indicate better screen performance. Calculated as described by Truchon, J. F; Bayly, C. I. J. Chem. Inf. Model. 2007, 47, 488-508, Equation (18); EF-Enrichment Factor, calculated with respect to the number of total ligands. $E F=(a / n) /(A / N)$, where $a$ is the number of actives found in sample size $\mathrm{n}, \mathrm{A}$ is the total number of actives, and $\mathrm{N}$ is the total number of ligands (decoys and actives).; $\mathrm{EF}^{*}-$ Enrichment factor for recovering $\mathrm{x} \%$ of the known actives, defined as the fraction of the actives recovered divided by the faction of decoys recovered at that point. This value gives the relative probability that a compound recovered is an active rather than a decoy. Because the enrichment factors are computed using the fractions of actives and decoys recovered, they are independent of the absolute and relative numbers of actives and decoys screened.; $\mathrm{EF}^{\prime}$-modified enrichment factor defined using the average of the reciprocals of the $\mathrm{EF}^{*}$ enrichment factors for recovering the first aa $\%$ of the known actives. $\mathrm{EF}^{\prime}(\mathrm{x})$ will be larger than $\mathrm{EF}^{*}(\mathrm{x})$ if the actives in question come relatively early in the sequence, and smaller if they come relatively late.; Eff-efficiency in distinguishing actives from decoys on an absolute scale of 1 (perfect; all actives come before any decoys) to -1 (all decoys come before any actives); a value of 0 means that actives and decoys were recovered at equal proportionate rates." [25]. 


\section{Conclusions}

The best pharmacophore hypothesis has the following features: one hydrogen bond donor (D), three aromatic rings $(\mathrm{R})$, and one hydrophobic $(\mathrm{H})$ region (Figure 1). The evaluation and the validation of this hypothesis has been done by applying the "Atom based QSAR module" and the "Validate hypothesis workflow". The 3D-QSAR model built using DRRRH hypothesis shows significant statistically parameters, such as: a correlation coefficient, $R^{2}$ of 0.90 for the training set and a predictive correlation coefficient, $\mathrm{Q}^{2}$ of 0.86 . The DRRRH hypothesis was scored and the reliable metrics (ROC of 1; RIE of 17.97 and AUAC of 0.99) were obtained. From the Figure $3 b$ we can see that the inactive compounds are missing one pharmacophore feature which is found in the active compounds (the hydrophobic H4 centroid), which lead to the conclusion that this characteristic may be very important for the biological activity of the ligands. Further, databases of compounds can be screened in searching of molecules which present the pharmacophoric features that match this hypothesis, in order to predict novel porcupine inhibitors with potential anticancer activity, against Wnt signaling pathway.

Acknowledgments: This work was financially supported by the Project No. 1.1 of the Institute of Chemistry. We thank Chemaxon Ltd. for providing the academic license and to Dr. Ramona Curpan (Institute of Chemistry), for providing access to Schrödinger software acquired through the PN-II-RU-TE-2014-4-422 projects funded by CNCS-UEFISCDI. Romania.

Author Contributions: A.B. conceived and designed the computational framework of the study, A.B. and L.C performed all in silico experiments. All authors contributed to the writing of the manuscript and approved its content.

Conflicts of Interest: The authors declare no conflict of interest.

\section{References}

1. Xu, Z.; Li, J.; Wu, Y.; Sun, Z.; Luo, L.; Hu, Z.; He, S.; Zheng, J.; Zhang, H.; Zhang, X. Design, synthesis, and evaluation of potent Wnt signaling inhibitors featuring a fused 3-ring system. Eur. J. Med. Chem. 2016, 108, 154-165, doi:10.1016/j.ejmech.2015.11.026.

2. Madan, B.; Ke, Z.; Harmston, N.; Ho, S.Y.; Frois, A.O.; Alam, J.; Jeyaraj, D.A.; Pendharkar, V.; Ghosh, K.; Virshup, I.H.; et al. Wnt addiction of genetically defined cancers reversed by PORCN inhibition. Oncogene 2016, 35, 2197-2207, doi:10.1038/onc.2015.280.

3. Lum, L.; Clevers, H. The Unusual Case of Porcupine. Science 2012, 337, 922-923, doi:10.1126/science.1228179.

4. Alonso, L.; Fuchs, E. Stem cells in the skin: Waste not, Wnt not. Genes Dev. 2003, 17, 1189-1200, doi:10.1101/gad.1086903.

5. Pinto, D.; Clevers, H. Wnt control of stem cells and differentiation in the intestinal epithelium. Exp. Cell Res. 2005, 306, 357-363, doi:10.1016/j.yexcr.2005.02.022.

6. Nemeth, M.J.; Mak, K.K.; Yang, Y.; Bodine, D.M. $\beta$-catenin expression in the bone marrow microenvironment is required for long-term maintenance of primitive hematopoietic cells. Stem Cells 2009, 27, 1109-1119, doi:10.1002/stem.32.

7. Cisternas, P.; Henriquez, J.P.; Brandan, E.; Inestrosa, N.C. Wnt signaling in skeletal muscle dynamics: Myogenesis, neuromuscular synapse and fibrosis. Mol. Neurobiol. 2013, 49, 574-589, doi:10.1007/s12035013-8540-5.

8. Pecinas-Slaus, N. Wnt signal transduction pathway and apoptosis: A review. Cancer Cell. Int. 2010, 10, 22, doi:10.1186/1475-2867-10-22.

9. Kahn, M. Can we safely target the WNT pathway? Nat. Rev. Drug Discov. 2014, 13, 513-532, doi:10.1038/nrd4233.

10. Porfiri, E.; Rubinfeld, B.; Albert, I.; Hovanes, K.; Waterman, M.; Polakis, P. Induction of a $\beta$-catenin-LEF-1 complex by Wnt-1 and transforming mutants of $\beta$-catenin. Oncogene 1997, 15, 2833-2839, doi doi:10.1038/sj.onc.1201462.

11. Anastas, J.N.; Moon, R.T. WNT signalling pathways as therapeutic targets in cancer. Nat. Rev. Cancer 2013, 13, 11-26, doi:10.1038/nrc3419. 
12. Schinner, S. Wnt-signalling and the metabolic syndrome. Horm. Metab. Res. 2009, 41, 159-163, doi:10.1055/s0028-1119408.

13. Dees, C.; Distler, J.H. Canonical Wnt signaling as a key-regulator of fibrogenesis-Implications for targeted therapies? Exp. Dermatol. 2013, 22, 710-713, doi:10.1111/exd.12255.

14. Inestrosa, N.C.; Montecinos-Oliva, C.; Fuenzalida, M. Wnt signaling: Role in Alzheimer disease and schizophrenia. J. Neuroimmune Pharmacol. 2012, 7, 788-807, doi:10.1007/s11481-012-9417-5.

15. Seshagiri, S.; Stawiski, E.W.; Durinck, S.; Modrusan, Z.; Storm, E.E.; Conboy, C.B.; Chaudhuri. S.; Guan, Y.; Janakiraman, V.; Jaiswal, B.S.; et al. Recurrent R-spondin fusions in colon cancer. Nature 2012, 488, 660-664, doi:10.1038/nature11282.

16. Cardona, G.M.; Bell, K.; Portale, J.; Gaffney, D.; Moy, C.; Platero, S.; Lorenzi, M.V.; Karker, J. Identification of R-Spondin Fusions in Various Types of Human Cancer. In Proceedings of the 105th Annual Meeting of the American Association for Cancer Research 2014, San Diego, CA, USA, 5-9 April 2014; Abstract no. 2408.

17. Covey, T.M.; Kaur, S.; Ong, T.T.; Proffitt, K.D.; Wu, P.Tan.; Virshup, D.M. PORCN Moonlights in a WntIndependent Pathway That Regulates Cancer Cell Proliferation. PLoS ONE 2012, 7, e34532, doi:10.1371/journal.pone.0034532.

18. Barrott, J.J.; Cash, G.M.; Smith, A.P.; Barrow, J.R.; Murtaugh, L.C. Deletion of mouse Porcn blocks Wnt ligand secretion and reveals an ectodermal etiology of human focal dermal hypoplasia/Goltz syndrome. Proc. Natl. Acad. Sci. USA 2011, 108, 12752-12757, doi:10.1073/pnas.1006437108.

19. Schrödinger Release 2018-1: Phase; Schrödinger, LLC: New York, NY, USA, 2018.

20. Schrödinger Release 2018-1: LigPrep; Schrödinger, LLC: New York, NY, USA, 2018.

21. Shelley, J.C.; Cholleti, A.; Frye, L; Greenwood, J.R.; Timlin, M.R.; Uchimaya, M. Epik: A software program for pKa prediction and protonation state generation for drug-like molecules. J. Comp. Aided Mol. Des. 2007, 21, 681-691, doi:10.1007/s10822-007-9133-z.

22. Schrödinger Release 2018-1: ConfGen; Schrödinger, LLC: New York, NY, USA, 2018.

23. Dixon, S.L.; Smondyrev, A.M.; Knoll, E.H.; Rao, S.N.; Shaw, D.E.; Friesner, R.A. PHASE: A new engine for pharmacophore perception, 3D QSAR model development, and 3D database screening: 1. Methodology and preliminary results. J. Comput. Aided Mol. Des. 2006, 20, 647-671, doi:10.1007/s10822-006-9087-6.

24. Schrödinger Release 2018-1: Phase Help-Atom-Based QSAR Panel; Schrödinger, LLC: New York, NY, USA, 2018.

25. Schrodinger Release 2018-1: Glide Help - Enrichment Calculator Panel; Schrödinger, LLC: New York, NY, USA, 2018.

(C) 2018 by the authors. Licensee MDPI, Basel, Switzerland. This article is an open access article distributed under the terms and conditions of the Creative Commons Attribution (CC BY) license (http://creativecommons.org/licenses/by/4.0/). 